\author{
Associate Professor Yang ZHAO, PhD \\ E-mail: zhaoyang2012@jlu.edu.cn \\ Northeast Asian Research Center, Jilin University \\ Ran WEI, Master Graduate \\ E-mail: w785505703@163.com \\ Northeast Asian Studies College, Jilin University \\ Professor Chongwen ZHONG, PhD (Corresponding Author) \\ E-mail: zhongchongwen@bipt.edu.cn \\ School of Economics \& Management, \\ Beijing Institute of Petrochemical Technology
}

\title{
RESEARCH ON SPATIAL SPILLOVER EFFECTS AND REGIONAL DIFFERENCES OF URBAN HOUSING PRICE IN CHINA
}

\begin{abstract}
After the global financial crisis in 2008, China's real estate market has gradually developed from "full prosperity" to "regional differentiation", manifested by the coexistence of high growth and high inventory, indicating a typical uneven regional development. This phenomenon made it inevitable to use the so-called "city-specific policies" to regulate the real estate market, and the linkage of housing prices and the measurement of spatial spillover effects resulting in regional differences in housing prices have become issues that urgently need to be clarified. This paper takes the urban housing prices of 266 prefecture-level cities in China from 2005 to 2017 as the main research object and measures the global and local correlations of urban housing prices by constructing a spatial weight matrix. Meanwhile, a Spatial Dubin Model is established to study the spillover effects of urban housing prices among regions with focus on geographical spans. This paper finds that when comparing the regional differences of spillover effects, it is not scientific enough to divide cities into regions according to the traditional way, and when the regions are divided according to urban agglomeration, the results are more representative and scientific.
\end{abstract}

Keywords: Urban Housing Price, Spillover Effect, Geographic Span, Urban Agglomeration, Regional Difference.

\section{JEL Classification: R12}

\section{Introduction}

Since the housing monetization reform in 1998, the development of China's real estate market can probably be divided into two stages with different characteristics based on the 2008 US subprime mortgage crisis. In many years before the outbreak of the global financial crisis, China's real estate market had developed rapidly and was in the ascendant. The housing prices and real estate

DOI: 10.24818/18423264/55.2.21.13 
investments had been rising rapidly, which had a profound impact on the livelihood of residents and the national economy. The government had habitually promulgated policies to stimulate the housing market to boost GDP growth. The housing price growth during this period was "ubiquitous", and the real estate market showed a nationwide "all-around prosperity". After the outbreak of the global financial crisis, the government and all sectors of society realized that the rapid development of the real estate market would inevitably cause consumers to have irrational expectations of the continued rise in housing prices, creating a large number of speculative demands not conducive to market stability, which could concealed immeasurable financial risks for economic growth. Since China's real estate market is a typical "policy market", the fluctuation of housing prices is less subject to market regulation and demand-supply constraints. Instead, it comes from the government's strong external intervention. The government began to use macroeconomic policies and housing control policies to regulate the market, hoping that the high housing price would fall back to the rational level. The Chinese real estate market in this period gradually showed the characteristics of high differentiation among regions. From the perspective of demand, there was a gradual differentiation among cities. The real estate market in the first-tier and the second-tier cities continued to heat up, and the inventory dropped significantly, whereas the real estate sales in the third-tier and the fourth-tier cities were sluggish and large amounts of inventory were accumulated. The housing price growth during this period was no longer "all-territorial"; it had become depressed in the context of rapid growth in some cities and high inventory in some other cities, showing a typical imbalance in regional development.

However, it is worth noting that the promotion of real estate market to GDP has been weakened, and even has a negative effect on the sustainable development of regional economy. On the one hand, the phenomenon of high inventories has led to an oversupply of the country's total inventory scale and accelerated the structural imbalances of urban development, which has caused a slowdown in China's regional economy, especially the county-level economy. On the other hand, in areas with high housing prices, the characteristics of high value preservation, high profitability and low threshold of real estate will lead excessive capital flowing into the real estate market when the capital is entering the real economy.. This will occupy the capital source of the development of the real economy, result in a "blood-drawing effect" and lead to the structural imbalance between the real economy and the real estate industry development. (Meng, 2018). This is a realistic problem that cannot be ignored in China at present, which is not common in the western real estate market.

In view of the above, China's cities, the "same-style" regulatory policies in the past will inevitably fail. The "city-specific policies" or even the "one city, one policy" have become the main tone of future real estate market regulations. But in fact, many of the urban housing control policies promulgated failed to achieve the expected results or even had a counterproductive effect. Housing prices in some 
Research on Spatial Spillover Effects and Regional Differences of Urban Housing Prices in China

cities still lingered at a high level, but the housing market in some cities was still sluggish. The implementation of the "city-specific policies" came to a bottleneck with limited control effects. Behind this reality there is a problem in urgent need to be solved: How shall we accurately measure the spatial linkage and spillover effects of housing prices in different cities and regions? Is there a "contagion mechanism" among the cities with high housing prices? This is undoubtedly the key point to describe the regional differentiation characteristics of China's real estate market and to examine the implementation effects of regional control policies. However, there is a logical paradox when we study the regional differences of housing price spillover effect, that is, when we consider the spatial spillover effect of housing price, we first default the method of regional division, and then measure the spillover effect on this basis. Then, when this kind of regional division is so general that it obscures the real characteristics of the regional differentiation of housing prices, the scientificity of the measured results should be re-considered. Therefore, how to reasonably delimit the boundary of "region" is also one of the issues that this paper hopes to explore.

In this paper, the geographical distance factor is considered in the construction of spatial weight, and the regional spatial correlation and spillover effects of urban housing price are calculated through spatial econometric models. Meanwhile, the results of different regional division methods are compared and analyzed. One way is to divide Chinese cities into four regions: East, West, East and northeast; the other way is to do the test according to the urban agglomerations. Specifically, this paper measures the spatial correlations through the global and local Moran's I index and then builds a Spatial Dubin Model (SDM) to estimate the spatial spillover effects of urban housing prices in China, and discuss the results according to different regions and different geographical spans.

The rest of the paper is organized as follows: The second part presents a literature review; the third part is a description of the data and methods applied; the fourth part offers the empirical test results of spatial correlations and spillover effects; the fifth part attempts to make comparative analysis and discussions among regions; and the last part is the conclusions of the paper.

\section{Literature Review}

Spatial correlations and spillover effects of housing prices have always been focuses of academic research on the spatial attributes of housing prices (Ding $\& \mathrm{Ni}, 2015)$. Meen (1996) was the first to use the spatial econometric models to analyze housing prices and found that there is a significant spatial correlation among real estate prices in various regions in the UK. Luo (2007), through an empirical analysis of the housing market in nine Australian cities, found that the housing prices among eight cities had "1-1-2-4" transmission characteristic. Wang et al. (2008) used the generalized impulse response function analysis to explore the correlation among housing prices in 26 cities in China.

In terms of spatial spillover effects of housing prices, Macdonald \& Taylor (1993) were the first to use co-integration analysis to investigate the interactive

DOI: 10.24818/18423264/55.2.21.13 
relationship among housing prices in the United Kingdom, and believed that housing prices in the southeast of the UK had a price-leading role and there is a "ripple effect" transmitted from the middle to the north. Clapp \& Tirtiroglu (1994) were the first to use the spatial econometric model to conduct research and believed that the geographically adjacent secondary market and the lag-phase prices would affect regional housing prices. Meen (1999) introduced the concept of "spatial dependence", and he believed that the regional transmission of housing prices had certain regularity. He also explained the reasons for the "ripple effect" of housing prices in terms of population migration, spatial arbitrage, transaction and search costs, etc. Pollakowski \& Ray (1997) analyzed housing prices at the regional level of metropolitan areas in the United States and found that there is a clear spatial correlation among housing prices of neighboring cities. Tsai (2015) found that in addition to housing prices, housing transaction stock also has a significant "ripple effect" among cities. Furthermore, Holly et al. (2011) found that the changes in housing prices in the City of London under the background of globalization would be affected by housing prices in New York of the United States. Milcheva \& Zhu (2015) pioneered to establish a matrix of spatial correlation based on the integration of multinational banks and explored the spatial relationship among housing prices in various countries.

With the gradual differentiation of China's real estate market among regions, the spatial characteristics and linkage effects of housing prices have attracted more and more attention from Chinese scholars. However, different scholars have different criteria for the division of regional markets in Chinese cities, and, at the same time, the measurement methods for spatial linkage characteristics and spillover effects vary as well. Wang et al. (2008) divided 26 cities in China into northern coastal region, central coastal region, southern coastal region, central region and western region. They used the impulse response function to analyze the relationship among the above-mentioned regions and defined 10 "core cities" with great influence. Liang \& Xing (2012) conducted tests by establishing a dynamic multi-factor model and found that the spillover transmission route is from the eastern coastal regions to the underdeveloped regions in China. Ding \& Ni (2015) measured the regional spatial relevance of 285 cities in China and estimated by using the spatial lag model and the spatial error model. Wang et al. $(2018)^{[23]}$ divided 70 cities into five levels, tiers I-V, and analyzed the linkage effect and information spillover effect by using a spillover index modeling method based on a Directed Acyclic Graph (DAG).

The above literatures have expanded the field of research on the spatial characteristics of housing prices. Many valuable results have been achieved in the research on regional spatial correlation and spillover effects in the housing market. However, there are still some areas that need to be studied in depth. On the one hand, the high regional differentiation of China's housing prices mainly stems from the vast distribution of Chinese cities and the imbalance of regional economic development, and the volatility of China's housing prices shows more 
Research on Spatial Spillover Effects and Regional Differences of Urban Housing Prices in China

characteristics over time, so only by extending the time interval of empirical research and increasing the number of city samples as much as possible can we analyze the unique characteristics of the current market as much as possible. On the other hand, the research on the spatial correlation mostly takes the spatial proximity of cities into account but lacks consideration of geographic distance characteristics. However, only when more consideration is given to spatial scale will setting errors and estimation biases be avoided as much as possible.

\section{Data and Methodology}

Variable Selection and Data Processing

This paper selects relevant data of 266 prefecture-level cities in China from 2005 to 2017 as the research object. When picking the explained variables, the average sales price of urban commercial housing price (HP) is selected as the representative of urban housing price variable. For the selection of the explanatory variables, the supply factors, demand factors, urban scale effects and real estate market difference factors are incorporated in the model, taking Yu (2010), Wang et al. (2013), Li (2014) and Dong et al. (2016) as references. We select four main explanatory variables and two control variables, which are listed as Table 1:

Table 1. Variable list and description

\begin{tabular}{cc}
\hline Name & Variable description \\
\hline HP & Average sales price of urban commercial housing prices \\
INC & Per capita disposable income of urban residents \\
HSA & Commercial housing sold area per square kilometer of land in the \\
urban built-up area \\
UPD & Urban population density \\
HI & Amount of housing investment in real estate development \\
GR & Greening rate of urban built-up areas \\
MBED & Number of medical beds in health institutions \\
\hline
\end{tabular}

Furthermore, in order to eliminate heteroscedasticity and reduce the impact of raw data fluctuations on the accuracy of the model estimation, this paper takes logarithm processing of all variable data except urban population density and urban built-up area greening rate, and a unit root test is carried out to the data series after the logarithm to ensure its stationarity. The test results are shown in Table 2.

Table 2. Unit root test results

\begin{tabular}{ccc}
\hline \multirow{2}{*}{ Variable name } & \multicolumn{2}{c}{ Statistic } \\
\cline { 2 - 3 } & LLC & IPS \\
\hline $\ln H P$ & -25.3944 & -5.2842 \\
$\ln I N C$ & $(0.0000)$ & $(0.0000)$ \\
$\ln H A S$ & -41.9028 & -12.9983 \\
& $(0.0000)$ & $(0.0000)$ \\
& -19.6923 & -10.7566
\end{tabular}

DOI: 10.24818/18423264/55.2.21.13 
Yang Zhao, Ran Wei, Chongwen Zhong

\begin{tabular}{ccc}
\hline & $(0.0000)$ & $(0.0000)$ \\
$U P D$ & -15.3997 & -6.1453 \\
& $(0.0000)$ & $(0.0000)$ \\
& -28.9086 & -15.1228 \\
$\ln M B E D$ & $(0.0000)$ & $(0.0000)$ \\
$\ln H I$ & -13.3989 & -4.1573 \\
& $(0.0000)$ & $(0.0000)$ \\
& -31.5296 & -11.9497 \\
\hline
\end{tabular}

\section{Moran's I Index for Measuring Spatial Correlation}

Only by confirming the spatial correlation among urban housing prices can we further investigate the contagion mechanism and spillover effect in space, so we need to use the Moran's I index, which can describe the spatial correlation, for a measurement. This paper draws on some of the research results of Ding \& $\mathrm{Ni}$ (2015) and uses the Exploratory Spatial Data Analysis (ESDA) as an effective tool to measure the global Moran's I index and the local Moran's I index of different spatial unit observations to reveal the spatial correlation characteristics of Chinese urban housing prices.

The formula for calculating the global Moran's I index is as follows:

$$
\text { Moran's } I=\frac{N \sum_{i=1}^{N} \sum_{j=1}^{N} w_{i j}\left(x_{i}-\bar{x}\right)\left(x_{j}-\bar{x}\right)}{\sum_{i=1}^{N} \sum_{j=1}^{N} w_{i j} \sum_{i=1}^{N}\left(x_{i}-\bar{x}\right)^{2}}=\frac{\sum_{i=1}^{N} \sum_{j=1}^{N} w_{i j}\left(x_{i}-\bar{x}\right)\left(x_{j}-\bar{x}\right)}{S^{2} \sum_{i=1}^{N} \sum_{j=1}^{N} w_{i j}}
$$

Among them, $S^{2}=\frac{1}{N} \quad{ }_{i=1}^{N}\left(x_{i} \quad \bar{x}\right)^{2}, \bar{x}=\frac{1}{N} \sum_{i=1}^{N} x_{i} \cdot x_{i}$ is the observed value of the spatial unit i; $N$ represents the number of spatial units; and $w_{i j}$ represents the elements of the $N \quad N$ non-negative spatial weight matrix $W$. The range of the Moran's I index is [-1,1], and the absolute value of the index shows the strength of the spatial correlation. Generally, the standardized statistic $Z$ is used to test the significance of the global Moran's I index, which can be expressed as the following formula:

$$
\begin{aligned}
& Z(\text { Moran's } I)=\frac{\text { Moran's } I \quad E(\text { Moran's } I)}{\sqrt{\operatorname{VAR}(\text { Moran's } I)}} \\
& E(\text { Moran's } I)=\frac{1}{N 1}
\end{aligned}
$$

The global Moran's I index can generally explain the global spatial autocorrelation of related variables among cities, but it cannot reflect the local characteristics of the correlation among cities in various regions. In this case, the local Moran's I index is used to explain the local characteristics of the correlation variables.

The formula for calculating the local Moran's I index is as follows: 
Research on Spatial Spillover Effects and Regional Differences of Urban Housing Prices in China

$$
\text { Moran's } I_{i}=\frac{\left(x_{i} \quad \bar{x}\right)}{S^{2}} \quad{ }_{j=1}^{N} w_{i j}\left(x_{j} \quad \bar{x}\right)
$$

It can be seen from Formula 4 that the local Moran's I index measures the degree of correlation between the i-th spatial unit and its surrounding spatial units. In general, there are the following two scenarios:

a. When Moran's $I_{i}>0$, it means that the spatial unit has positive correlation characteristics.

b. When Moran's $I_{i}<0$, it means that the spatial unit has negative correlation characteristics.

\section{Identification and Construction of the Spatial Panel Data Model}

The construction of the spatial weight matrix serves as the premise and basis for the estimation of the housing space model. There are generally three construction methods, namely, the one based on the spatial proximity standard, the one based on the spatial distance standard, and the one based on the economic distance standard. At present, most of the existing researches are based on the first two standards to construct the corresponding spatial weight matrix. The spatial proximity criterion maintains that there is a significant mutual influence between two geographically bordered areas (with a common boundary in space), and this mutual influence does not exist or is not significant between geographically nonbordered areas. The spatial distance standard holds that all regions have a certain spatial relationship, and the strength of the spatial correlation among the regions is related to the distance intervals among the regions. The spatial correlation among regions will be weakened with the increase of the distance intervals among regions. The meaning of the spatial distance standard is more in line with the first law of geography than the spatial proximity standard, while it has a strict exogenous advantage compared with the economic distance standard. Therefore, this paper adopts the spatial distance standard to construct the spatial weights required by the empirical content, selects $400 \mathrm{KM}, 800 \mathrm{KM}, 1200 \mathrm{KM}$ and $1600 \mathrm{KM}$ to construct the spatial weights, and uses the Geoda software to construct the spatial weight matrix for the distance of $400-1600 \mathrm{KM}^{1}$, assuming that the elements in the spatial weight matrix satisfy the following:

$$
w_{i j}= \begin{cases}1 & i \neq j \\ 0 & i=j\end{cases}
$$

Among them, $w_{i j}=1 / d_{i j}, d_{i j}$ refers to the geographic distance among cities, and the reciprocal of the distance reflects the attenuation relationship between the role and the distance among cities.

\footnotetext{
${ }^{1}$ The reason why $400 \mathrm{KM}$ is selected as the minimum threshold and considered as the increments is that every city has at least one neighboring city if the distance is not less than that. (Ding \& Ni, 2015)
}

DOI: 10.24818/18423264/55.2.21.13 
In the identification and selection of spatial measurement models, the spatial error panel data model (SEM), the spatial lag panel data model (SLM) and the spatial Dubin panel data model (SDM) are common forms of spatial panel data models. The expressions of these three models are as follows:

$$
\begin{aligned}
& Y_{i t}=X_{i t}+{ }_{i}+v_{t}+{ }_{i t}, \quad{ }_{i t}={ }_{j=1}^{N} w_{i j}+{ }_{i t} \\
& Y_{i t}={ }_{j=1}^{N} w_{i j} Y_{j t}+X_{i t}+{ }_{i}+v_{t}+{ }_{i t} \\
& Y_{i t}={ }_{j=1}^{N} w_{i j} Y_{j t}+X_{i t}+{ }_{j=1}^{N} w_{i j} X_{j t}+{ }_{i}+v_{t}+{ }_{i t}
\end{aligned}
$$

In Formula (6)-(8), $Y_{i t}$ is the observed value of the explained variable of the spatial unit $i(i=1, \cdots, N)$ in the period $t(t=1, \cdots T) ; w_{i j}$ is the $i$ row and the $j$ column element of the spatial weight matrix where $N \quad N$ is greater than zero; $X_{i t}$ is the explanatory variables of the model; and are the estimated parameters of the model; , and represent the spatial error coefficient, the spatial lag coefficient and the spatial Dubin coefficient respectively, and they also all represent the spatial spillover effect coefficients; ${ }_{i}$ represents the individual effect; ${ }_{t}$ represents the time effect; ${ }_{i t}$ refers to the random disturbance item; ${ }_{i t}$ represents the residual item of the spatial autocorrelation, which depends on ${ }_{j} t$ and ${ }_{i t} ;{ }_{j t}$ represents the residual of the surrounding units; and ${ }_{i t}$ indicates the white noise process.

Furthermore, the Hausman test chooses to use the fixed-effect model. And the model is identified by referring to the ideas of LeSage \& Pace (2009). Through the LR test, it determines whether the SDM will be degenerated into a SLM or a SEM. The test results are shown in Table 3.

Table 3. LR test results of national regional spatial panel data model under different geographical span

\begin{tabular}{ccccc}
\hline Geographical & \multicolumn{2}{c}{ LR test results of SDM \& SLM } & \multicolumn{2}{c}{ LR test results of SDM \& SEM } \\
\cline { 2 - 5 } Span & LR & P & LR & P \\
\hline $400 \mathrm{KM}$ & 66.88 & 0.00 & 298.99 & 0.00 \\
800KM & 45.33 & 0.00 & 147.45 & 0.00 \\
$1200 \mathrm{KM}$ & 38.06 & 0.00 & 88.86 & 0.00 \\
$1600 \mathrm{KM}$ & 41.30 & 0.00 & 74.67 & 0.00 \\
\hline
\end{tabular}

It can be seen from Table 3 that under the geographic span of 400$1600 \mathrm{KM}$, the two LR tests are both significant at the $1 \%$ significance level, indicating that the SDM should be adopted to test the spillover effect. Based on 
Research on Spatial Spillover Effects and Regional Differences of Urban Housing Prices in China

equation (8) and the indicators selected in this paper, the following SDM is constructed as the benchmark model for empirical testing in this paper, as shown in equation (9):

$$
\begin{aligned}
& \ln H P_{i t}={ }_{j=1}^{N} w_{i j} \ln H P_{j t}+{ }_{1} \ln I N C_{i t}+{ }_{2} \ln H S A_{i t}+{ }_{3} U P D_{i t}+{ }_{4} G R_{i t} \\
& +{ }_{5} \ln M B E D_{i t}+{ }_{6} \ln H I_{i t}+{ }_{1}{ }_{j=1}^{N} w_{i j} \ln I N C_{j t}+{ }_{2}{ }_{j=1}^{N} w_{i j} \ln H S A_{j t} \\
& +{ }_{3}{ }_{j=1}^{N} w_{i j} U P D_{j t}+{ }_{4}{ }_{j=1}^{N} w_{i j} G R_{j t}+{ }_{5}{ }_{j=1}^{N} w_{i j} \ln M B E D_{j t} \\
& \quad+{ }_{6}{ }_{j=1}^{N} w_{i j} \ln H I_{j t}+{ }_{i}+{ }_{t}+{ }_{i t}
\end{aligned}
$$

Among them, represents the spatial spillover effect coefficient; represent the influence of the explanatory variables in the region on the housing price in the region; and ${ }_{1}{ }^{-}{ }_{6}$ represent the influence of the explanatory variables in the neighboring area on the housing price in the region. The meanings of the other variables are the same as in Formula (8).

\section{Results of Spatial Correlation and Spillover Effect of Urban Housing price in China}

\section{Global Spatial Correlation Measurements}

This paper takes China's 266 prefecture-level cities as the spatial units for the study, sets the distance threshold of 400KM for the study ${ }^{2}$, and uses the Geoda software to measure the global Moran's I index for housing prices of distances of 400KM, 800KM, 1200KM and 1600KM each among cities of China between 2005 and 2017. Under the four distance settings, the global Moran's I index of China's housing prices from 2005 to 2017 were all greater than zero, and the P values are all less than 0.05 , indicating that China's urban housing prices had a significant spatial positive correlation with 95\% confidence. The measurement results are drawn and shown in Figure 1.

\footnotetext{
${ }^{2}$ Only when the threshold is greater than or equal to 328.44 kilometers can it be ensured that every city in the country has at least one neighbor. Therefore, this paper selects 400 as the minimum distance threshold for measuring the Moran's I index and the local Moran's I index.
}

DOI: 10.24818/18423264/55.2.21.13 


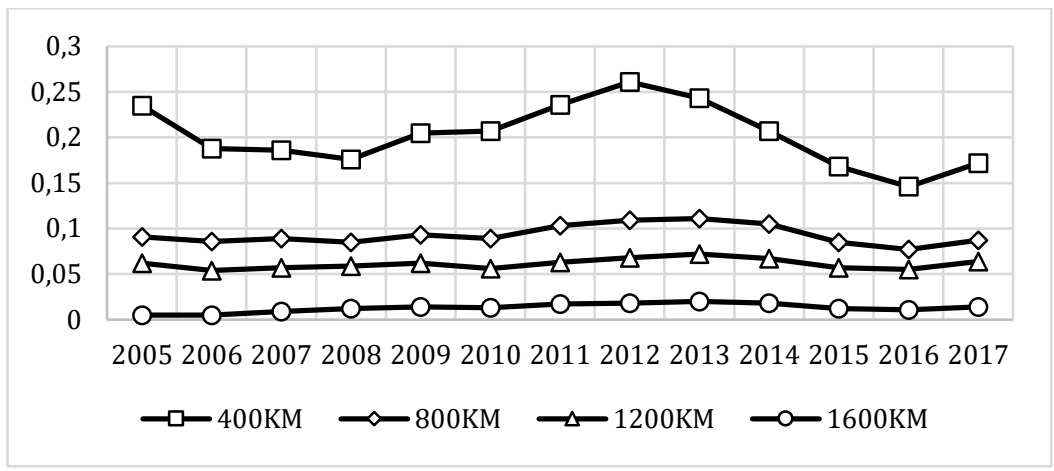

Figure 1. Global Moran's I index trend of urban house prices in China under different distance settings

It can be seen from Figure 1 that as the set distance increases, the global Moran's I index of Chinese urban housing prices continues to decrease. Taking the year of 2017 as an example, when the set distances were 400KM, 800KM, $1200 \mathrm{KM}$ and $1600 \mathrm{KM}$, the Moran's I index of Chinese urban housing prices were $0.172,0.087,0.064$ and 0.014 respectively. That is, as the area decreases, the spatial correlation of housing prices among neighboring regions will gradually increase, which shows that, as a whole, the spatial distribution of housing prices in Chinese cities is governed by the first law of geography. In addition, the global Moran's I index trend indicates that the positive spatial correlation of urban housing prices increased first and then decreased during 2005-2017.

\section{Local Spatial Correlation Measurements}

The global Moran's I index reveals the spatial correlation of China's urban housing market in general. However, considering China's vast territory and significant regional differences, urban housing prices may have an "atypical" phenomenon that cannot be reflected in the global Moran's I index due to local correlations. This paper measures the local Moran's I index of China's urban housing market under a geographical span of $800 \mathrm{KM}$, and sets four-year intervals to observe the Moran scatter plots of urban housing prices of these 266 prefecturelevel cities in 2005, 2009, 2013 and 2017, as shown in Figure 2.

In Figure 2, the cities located in Quadrant I through Quadrant IV are scattered in the patterns of high-high $(\mathrm{H}-\mathrm{H})$, low-high $(\mathrm{L}-\mathrm{H})$, low-low $(\mathrm{L}-\mathrm{L})$, and high-low (H-L). Most prefecture-level cities in China are found in the first and the third quadrants, which further show that the housing prices in Chinese cities are spatially clustered. Prefecture-level cities with higher housing prices are adjacent to each other, and those with lower housing prices are adjacent to each other. In general, most of the cities with the high-high distribution pattern sit in the eastern region, while the cities with the low-low distribution pattern are mostly located in the western and northeastern regions, and the cities with the low-high distribution pattern are mostly found in the central region. 
Research on Spatial Spillover Effects and Regional Differences of Urban Housing Prices in China
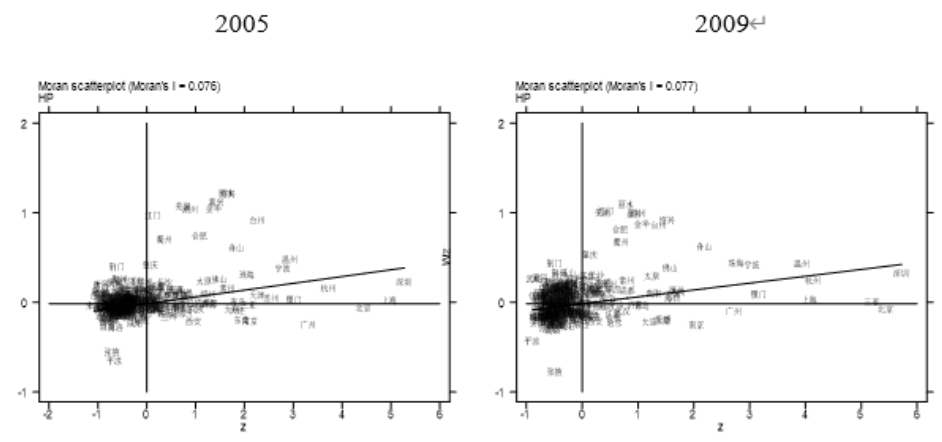

2013

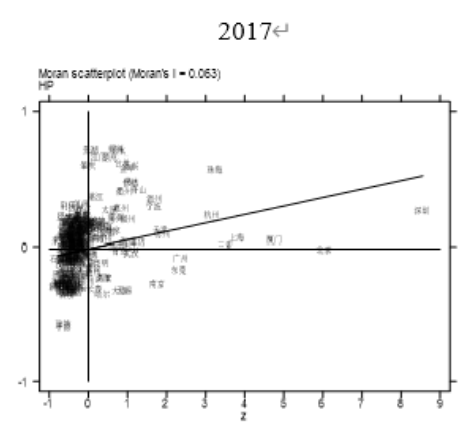

Figure 2. Local Moran's I index scatter chart of China's urban housing prices

From 2005 to 2017, the number of the H-H distributed cities increased from 39 to 43. The reason for this phenomenon may be that the economic development of the Yangtze River Delta and the Pearl River Delta had always been at a high level, which will attracts capital and people inflows. With the influx of people, the demand for housing will increase accordingly. Some people who cannot afford high housing prices choose to buy houses in neighboring prefecturelevel cities or provinces, resulting in certain increases of housing prices in surrounding cities. The number of the L-L distributed cities increased from 67 to 90. The cities in northeast areas contribute to this number mainly. The number of the L-H distributed cities increased from 27 to 34 . This change was mainly reflected in the Pearl River Delta and its surrounding cities. The number of the H-L distributed cities increased from 13 to 16 . This change was mainly reflected in the northeast and western regions. The number of cities in the western region first increased and then decreased, while the number of cities in the northeast region increased significantly from 2005 to 2009.

Spillover Effects by Geographical Span in the National Samples

Furthermore, based on the data of the 266 cities in China from 2005 to 2017, according to Formula (9), the spatial spillover effects of urban housing prices were tested under four different geographic spans of 400KM, 800KM, 1200KM and 1600KM. The test results are shown in Table 4.

DOI: 10.24818/18423264/55.2.21.13 
Yang Zhao, Ran Wei, Chongwen Zhong

Table 4. Results of spatial spillover effect of urban housing prices in China under different geographical spans

\begin{tabular}{|c|c|c|c|c|}
\hline \multirow{2}{*}{$\begin{array}{c}\text { Variable } \\
\text { /Coefficient }\end{array}$} & \multicolumn{4}{|c|}{ Geographical Span } \\
\hline & $0-400 \mathrm{KM}$ & $0-800 \mathrm{KM}$ & $0-1200 \mathrm{KM}$ & $0-1600 \mathrm{KM}$ \\
\hline \multirow{2}{*}{$\ln I N C$} & $0.1092^{* * *}$ & $0.0898^{* *}$ & $0.0800^{* *}$ & $0.0889^{* *}$ \\
\hline & $(0.0378)$ & $(0.0369)$ & $(0.0366)$ & $(0.0365)$ \\
\hline \multirow{2}{*}{$\ln H A S$} & $-0.0486^{* * *}$ & $-0.0482^{* * * *}$ & $-0.0479^{* * * *}$ & $-0.0490^{* * *}$ \\
\hline & $(0.0064)$ & $(0.0064)$ & $(0.0064)$ & $(0.0073)$ \\
\hline \multirow{2}{*}{$U P D$} & $0.0111^{* * * *}$ & $0.0119^{* * * *}$ & $0.0123^{\text {**** }}$ & $0.0127^{* * * *}$ \\
\hline & $(0.0037)$ & $(0.0037)$ & $(0.0037)$ & $(0.0207)$ \\
\hline \multirow{2}{*}{$G R$} & $0.0004^{*}$ & 0.0003 & 0.0003 & 0.0002 \\
\hline & $(0.0002)$ & $(0.0002)$ & $(0.0002)$ & $(0.0002)$ \\
\hline \multirow{2}{*}{$\ln M B E D$} & $0.1012^{* * *}$ & $0.1092^{* * * *}$ & $0.1195^{\text {**** }}$ & $0.1167^{\text {**** }}$ \\
\hline & $(0.0213)$ & $(0.0213)$ & $(0.0213)$ & $(0.0212)$ \\
\hline \multirow{2}{*}{$\ln H I$} & $0.0383^{* * *}$ & $0.0356^{\text {*** }}$ & $0.0369^{* * * *}$ & $0.0380^{* * * *}$ \\
\hline & $(0.0074)$ & $(0.0073)$ & $(0.0073)$ & $(0.0073)$ \\
\hline \multirow{2}{*}{$\mathrm{W}^{*} \ln I N C$} & 0.0651 & -0.0172 & -0.0832 & $-0.2592^{* * *}$ \\
\hline & $(0.0538)$ & $(0.0628)$ & $(0.0721)$ & $(0.0819)$ \\
\hline \multirow{2}{*}{$\mathrm{W}^{*} \ln H A S$} & 0.0095 & 0.0182 & 0.0268 & 0.0310 \\
\hline & $(0.0153)$ & $(0.0192)$ & $(0.0218)$ & $(0.0234)$ \\
\hline \multirow{2}{*}{$\mathrm{W}^{*} U P D$} & -0.0085 & -0.0060 & -0.0134 & -0.0371 \\
\hline & $(0.0115)$ & $(0.0186)$ & $(0.0248)$ & $(0.0274)$ \\
\hline \multirow{2}{*}{$\mathrm{W}^{*} G R$} & 0.0002 & -0.0004 & -0.0007 & 0.0027 \\
\hline & $(0.0008)$ & $(0.0011)$ & $(0.0018)$ & $(0.0019)$ \\
\hline \multirow{2}{*}{$\mathrm{W}^{*} \ln M B E D$} & -0.0490 & -0.0589 & -0.0543 & 0.0613 \\
\hline & $(0.0385)$ & $(0.0457)$ & $(0.0537)$ & $(0.0610)$ \\
\hline \multirow{4}{*}{$\mathrm{W}^{*} \ln H I$} & $0.0888^{* * * *}$ & $0.0885^{* * * *}$ & $0.0878^{* * * *}$ & $0.0894^{* * * *}$ \\
\hline & $(0.0155)$ & $(0.0199)$ & $(0.0225)$ & $(0.0251)$ \\
\hline & $0.5240^{* * * *}$ & $0.6319^{* * * *}$ & $0.6892^{\text {**** }}$ & $0.7240^{* * * *}$ \\
\hline & $(0.0268)$ & $(0.0360)$ & $(0.0428)$ & $(0.0470)$ \\
\hline$R^{2}$ & 0.8203 & 0.8257 & 0.8284 & 0.8304 \\
\hline Sigma $^{2}$ & 0.0167 & 0.0167 & 0.0168 & 0.0167 \\
\hline
\end{tabular}

Note: $* * *, * *$ and $*$ are significant at $1 \%, 5 \%$ and $10 \%$ significance levels, respectively.

It can be seen from the results that the spatial spillover effect of urban housing prices in China is significantly positive. Under the four set distances, the spillover coefficients are $0.5240,0.6319,0.6892$ and 0.7240 . It can be seen that the spatial spillover effect of housing prices in Chinese cities is definite, and it is showing the tendency that its intensity steps up as the geographic span increases. This may indicate to a certain extent that the changes in housing prices in Chinese cities are not only affected by relevant economic factors in the region, and they are 
Research on Spatial Spillover Effects and Regional Differences of Urban Housing Prices in China

also subject to different degrees of influence of surrounding cities and distant cities.

\section{Further Discussions on Regional Differences of Spillover Effects}

In order to further explore the spatial spillover effects of housing prices in China from the perspective of regional differences, this paper tries two regional division methods and compares the empirical results of the two divisions. The first method divides the 266 cities into four economic regions: the east, the central, the west and the northeast. The geographical spans are still set to $400 \mathrm{KM}, 800 \mathrm{KM}$, $1200 \mathrm{KM}$ and 1600KM.. The results of spillover effect are shown in Table 5.

Table 5. Regression results of different geographical spans: Eastern, central, Western and Northeast China

\begin{tabular}{ccccc}
\hline & \multicolumn{3}{c}{ Eastern region } \\
Geographical span & $0-400 \mathrm{KM}$ & $0-800 \mathrm{KM}$ & $0-1200 \mathrm{KM}$ & $0-1600 \mathrm{KM}$ \\
\hline & $0.5914^{* * *}$ & $0.6373^{* * *}$ & $0.6396^{* * *}$ & $0.6382^{* * *}$ \\
$R^{2}$ & $(0.0431)$ & $(0.0490)$ & $(0.0553)$ & $(0.0601)$ \\
Sigma $^{2}$ & 0.8346 & 0.8422 & 0.8484 & 0.8516 \\
Other variables & 0.0151 & 0.0148 & 0.0148 & 0.0147 \\
\hline \multicolumn{5}{c}{ Control } \\
\hline
\end{tabular}

\begin{tabular}{ccccc}
\hline & \multicolumn{5}{c}{ Central region } \\
Geographical span & $0-400 \mathrm{KM}$ & $0-800 \mathrm{KM}$ & $0-1200 \mathrm{KM}$ & $0-1600 \mathrm{KM}$ \\
\hline & $0.6945^{* * *}$ & $0.7559^{* * *}$ & $0.7641^{* * *}$ & $0.7647^{* * *}$ \\
$R^{2}$ & $(0.0426)$ & $(0.0508)$ & $(0.0525)$ & $(0.0527)$ \\
Sigma $^{2}$ & 0.8544 & 0.8535 & 0.8528 & 0.8525 \\
Other variables & 0.0130 & 0.0134 & 0.0135 & 0.0136 \\
\hline \multicolumn{5}{c}{ Western region } \\
Geographical span & $0-400 \mathrm{KM}$ & $0-800 \mathrm{KM}$ & $0-1200 \mathrm{KM}$ & $0-1600 \mathrm{KM}$ \\
\hline & $0.4815^{* * *}$ & $0.5285^{* * *}$ & $0.5835^{* * *}$ & $0.6010^{* * *}$ \\
$R^{2}$ & $(0.0496)$ & $(0.0540)$ & $(0.0611)$ & $(0.0681)$ \\
Sigma $^{2}$ & 0.8264 & 0.8283 & 0.8307 & 0.8347 \\
Other variables & 0.0172 & 0.0170 & 0.0170 & 0.0169 \\
\hline \multicolumn{5}{c}{ Control } \\
Geographical span & $0-400 \mathrm{KM}$ & $0-800 \mathrm{KM}$ & $0-1200 \mathrm{KM}$ & $0-1600 \mathrm{KM}$ \\
\hline & $0.3838^{* * *}$ & $0.3321^{* * *}$ & $0.3424 * * *$ & $0.3406^{* * *}$ \\
$R^{2}$ & $(0.0764)$ & $(0.1075)$ & $(0.1150)$ & $(0.1153)$ \\
Sigma $^{2}$ & 0.8216 & 0.8290 & 0.8295 & 0.8296 \\
Other variables & 0.0109 & 0.0108 & 0.0108 & 0.0108 \\
\hline
\end{tabular}

Note: $* * *, * *$, and $*$ are significant at $1 \%, 5 \%$ and $10 \%$ significance levels, respectively.

DOI: 10.24818/18423264/55.2.21.13 
Yang Zhao, Ran Wei, Chongwen Zhong

It can be seen from Table 5 that the cities in the middle of China have the strongest housing price spillover effects, followed by the cities in the east, and then in the west, and the lowest is found in the northeast. The spillover effects of housing prices in central and western cities both increase with the increase of geographic spans. The spillover effect in the east reaches strongest at $0-1200 \mathrm{KM}$; it is volatile and becomes the strongest at $0-400 \mathrm{KM}$ in the northeast. There are several debatable questions here: First, the spatial correlation degree of housing prices in eastern cities is relatively the highest, but why is the fact that the spatial spillover effect is not as high as in central cities? Second, when the geographic span is too large, is it reasonable for the spillover effect to increase as the span increases? Third, does the western region affect the empirical results because of its relatively large geographic spans among cities? Actually, when we consider the spillover effect of housing prices, we first acquiesce in the division of regions before measuring it on this basis. Then, when this kind of regional division is too general that it obscures the real characteristics of the regional differentiation of housing prices, the scientificity of the measured results is worth validating.

Furthermore, we consider adopting the second method of regional division, which is the division according to urban agglomerations. This paper selects the Yangtze River Delta, the Pearl River Delta and the Beijing-Tianjin-Hebei urban agglomerations mainly located in the eastern region to observe the differences in housing price spillover effects among urban agglomerations. Specifically, the SDM is used to set thresholds for the Yangtze River Delta and the Pearl River Delta urban agglomerations at intervals of $150-500 \mathrm{KM}$ every $50 \mathrm{KM}$, and for the BeijingTianjin-Hebei urban agglomeration at $250-500 \mathrm{KM}$ every $50 \mathrm{KM}$ to conduct empirical analyses to observe the spatial spillover effect coefficients of housing prices in different regions. We choose the minimum geographic span of $250 \mathrm{KM}$ for the Beijing-Tianjin-Hebei urban agglomeration on the ground that only the minimum $249 \mathrm{KM}$ can ensure that every city has at least one neighboring city. We choose 500KM as the upper limit of the geographic span for all the three urban agglomerations because when the distance is longer, the radius will be large enough to cover all cities, and the empirical results will not change. The results are shown in Tables 6-8.

Table 6. Regression results of urban agglomeration in Yangtze River Delta under different geographical span

\begin{tabular}{ccccc}
\hline Geographical span & $0-150 \mathrm{KM}$ & $0-200 \mathrm{KM}$ & $0-250 \mathrm{KM}$ & $0-300 \mathrm{KM}$ \\
\hline & $0.4083^{* * *}$ & $0.4778^{* * *}$ & $0.5233^{* * *}$ & $0.5564 * * *$ \\
$R^{2}$ & $(0.0649)$ & $(0.0712)$ & $(0.0743)$ & $(0.0753)$ \\
Sigma $^{2}$ & 0.7486 & 0.7494 & 0.7488 & 0.7495 \\
Other variables & 0.0216 & 0.0213 & 0.0213 & 0.0210 \\
\hline
\end{tabular}


Research on Spatial Spillover Effects and Regional Differences of Urban Housing Prices in China

\begin{tabular}{ccccc}
\hline Geographical span & $0-350 \mathrm{KM}$ & $0-400 \mathrm{KM}$ & $0-450 \mathrm{KM}$ & $0-500 \mathrm{KM}$ \\
\hline & $0.5702^{* * *}$ & $0.5877 * * *$ & $0.5830^{* * *}$ & $0.5840 * * *$ \\
$R^{2}$ & $(0.0765)$ & $(0.0766)$ & $(0.0778)$ & $(0.0782)$ \\
Sigma $^{2}$ & 0.7505 & 0.7496 & 0.7510 & 0.7513 \\
Other variables & 0.0209 & 0.0209 & 0.0209 & 0.0209 \\
\hline \multicolumn{5}{c}{ Control } \\
Note: $* * *, * *$, and $*$ are significant at $1 \%, 5 \%$ and 10\% significance levels, respectively.
\end{tabular}

It can be seen from Table 6 that under the 150-500KM setting, the spillover effect is significant at the level of $1 \%$ and the coefficients under various distance settings are respectively $0.4083,0.4778,0.5233,0.5546,0.5702,0.5877$, 0.5830 and 0.5840 in the Yangtze River Delta urban agglomeration. We can find that the spillover coefficients display a trend of increasing first and then decreasing, which presents an inverted U-shape feature and reaches the best in a radius of $400 \mathrm{KM}$.

Table 7. Regression results of urban agglomerations in Pearl River Delta under different geographical spans

\begin{tabular}{ccccc}
\hline Geographical span & $0-150 \mathrm{KM}$ & $0-200 \mathrm{KM}$ & $0-250 \mathrm{KM}$ & $0-300 \mathrm{KM}$ \\
\hline & $0.4268^{* * *}$ & $0.4876^{* * *}$ & $0.4784^{* * *}$ & $0.3797 * * *$ \\
$R^{2}$ & $(0.0699)$ & $(0.0801)$ & $(0.0926)$ & $(0.1043)$ \\
Sigma $^{2}$ & 0.8861 & 0.8858 & 0.8960 & 0.9035 \\
Other variables & 0.0108 & 0.0109 & 0.0108 & 0.0106 \\
\hline Geographical span & $0-350 \mathrm{KM}$ & $0-400 \mathrm{KM}$ & $0-450 \mathrm{KM}$ & $0-500 \mathrm{KM}$ \\
\hline & $0.3500^{* * *}$ & $0.3135^{* * *}$ & $0.3127 * * *$ & $0.3127 * * *$ \\
$R^{2}$ & $(0.1110)$ & $(0.1140)$ & $(0.1140)$ & $0.1140)$ \\
Sigma $^{2}$ & 0.9047 & 0.9066 & 0.9066 & 0.9066 \\
Other variables & 0.0106 & 0.0104 & 0.0104 & 0.0104 \\
\hline
\end{tabular}

Note: $* * * * *$, and $*$ are significant at $1 \%, 5 \%$ and $10 \%$ significance levels, respectively.

It can be seen from Table 7 that under the 150-500KM setting, the spatial spillover effect of housing prices is significant at the level of $1 \%$ and the coefficients under various distance settings are respectively $0.4268,0.4876$, $0.4784,0.3797,0.3500,0.3135,0.3127$ and 0.3127 in the Pearl River Delta. The coefficients display a trend of increasing first and then decreasing, which shows an inverted U-shape feature and reaches the best in a radius of 200KM. After the radius reaches $400 \mathrm{KM}$, the spillover effect tends to be stable.

DOI: 10.24818/18423264/55.2.21.13 
Yang Zhao, Ran Wei, Chongwen Zhong

Table 8. Regression results of Beijing-Tianjin-Hebei Urban Agglomeration under different distance span

\begin{tabular}{ccccccc}
\hline $\begin{array}{c}\text { Geographical } \\
\text { span (KM) }\end{array}$ & $0-250$ & $0-300$ & $0-350$ & $0-400$ & $0-450$ & $0-500$ \\
\hline & -0.0423 & -0.0673 & -0.0756 & -0.0176 & -0.0442 & -0.0618 \\
$R^{2}$ & 0.9005 & 0.9010 & 0.9029 & 0.9020 & 0.9027 & 0.9041 \\
$\begin{array}{c}\text { Sigma }{ }^{2} \\
\text { Other variables }\end{array}$ & 0.0091 & 0.0090 & 0.0088 & 0.0089 & 0.0089 & 0.0087 \\
\hline \multicolumn{7}{c}{ Cote: ***,**, and * are significant at 1\%, 5\% and 10\% significance levels, respectively. }
\end{tabular}

It can be seen from Table 8 that under the $250-500 \mathrm{KM}$ setting, the spatial spillover effect is insignificant in the Beijing-Tianjin-Hebei urban agglomeration. In other words, in the eastern part of China, also an important core area of economy in north China, the spillover effect of its housing prices is rather weak on the contrary, and the transmission effect among urban housing prices is quite limited, and linkage and support cannot take shape. This is significantly different from the results of the Yangtze River Delta and the Pearl River Delta, which are also important urban agglomerations in the eastern region.

\section{Conclusions}

Based on the theoretical and empirical research in this paper, the following three main conclusions can be drawn:

First, it is found that there is an obvious spatial spillover phenomenon in urban housing prices in China, and, when the set geographic span increases from $400 \mathrm{KM}$ to $1600 \mathrm{KM}$, the spatial spillover effects still exist significantly. In other words, the spillover effect of urban housing prices not only exists among neighboring cities, but is also affected by housing prices in cities farther away to varying degrees.

Second, the test results of the spillover effect under different regional division methods are different. When the regions are divided according to the traditional eastern, central, western and northeastern regions, the significance and intensity of spillover effects are somewhat irrational. When we divide the regions by urban clusters and test the housing price spillover effects of the three major eastern urban agglomerations in the Yangtze River Delta, the Pearl River Delta and the Beijing-Tianjin-Hebei region, the results are more reasonable and scientific.

The third is also the most enlightening result of the paper. That is, the traditional division method of the eastern, central, western and northeastern regions is no longer sufficient to accurately represent the regional characteristics. When the representative city cluster is used as the regional division standard, the result is of more representative significance and scientificity. However, the above methods actually both have problems such as strong subjectivity. Therefore, "how to 
Research on Spatial Spillover Effects and Regional Differences of Urban Housing Prices in China

establish a validating standard, subdivide a large number of cities in China on the basis of this standard, and perform calculations on the basis of this division" has become a key scientific issue, pending full inquiries in subsequent researches.

Based on the research conclusions of this paper, we believe that the Chinese government should pay attention to the following in its future regulations of real estate market:

First, governments should adopt differentiated real estate regulating policies in different regions follow the "city-specific policies" or even the "one city, one policy", which will help the public to form relatively stable price expectations for the real estate market. For the "core cities" with significant spatial spillover effects of housing prices, China's national government should strengthen financial risk prevention and control.

Second, it is necessary to strengthen the growth pole role of the "metropolitan area". We must not forget to build the support function of hinterland cities when developing megacities and central cities. When promoting urban agglomeration construction, we should construct the metropolitan circles with a radius of 30-80 kilometers around the central city and build rail transit to connect the central cities in the metropolitan area and surrounding small and medium-sized cities. In doing so, it can not only strengthen the growth pole role of the central city, but also ensure the resilience and stability of the city in unexpected disasters.

Finally, it is necessary to enhance the flexibility of land and housing management to ensure the carrying capacity and development space of the central city. China's regional strategy is undergoing major changes. The supply of land and accommodation needs to be consistent with the direction of population flow so as to reduce the current mismatch between demand and supply in the land market. Based on regions as units, the mechanism of mutual capacitance and interoperability for construction land use increase/decrease should be established in urban and rural areas so as to facilitate cross-city and cross-province coordination.

\section{ACKNOWLEDGEMENTS}

This article is supported by National Natural Science Foundation of China (Grant Number: 71973051), and also the major project of the Key Research Base of Humanities and Social Sciences of the Ministry of Education (Grant Number: 16JJD790013).

\section{REFERENCES}

[1] Clapp, J.M., Tirtiroglu, D. (1994), Positive Feedback Trading and Diffusion of Asset Price Changes: Evidence from Housing Transactions. Journal of Economic Behavior \& Organization, 24(3): 337-355;

[2] Ding, R.X., Ni, P.F. (2015), Regional Spatial Linkage and Spillover Effect of House Prices of China's Cities- -Based on the Panel Data of 285 Cities from 2005 to 2012. Finance \& Trade Economics, (6): 136-150; 
Yang Zhao, Ran Wei, Chongwen Zhong

[3] Dong, J.C., Zhang, X., Zhou, K.C., Li, X.T. (2016), The Research on Real Estate Price Agglomeration and Heterogeneity in China Based on Spatial Econometrics. Systems Engineering-Theory \& Practice, 36(4): 875-883; [4] Holly, S., Pesaran, M.H., Yamagata, T. (2011), The spatial and Temporal Diffusion of House Prices in the UK. Journal of Urban Economics, 69(1): 2-23; [5] Lesage, J.P., Pace, R.K. (2009), Introduction to Spatial Econometrics. Taylor \& Francis Group, CRC Press;

[6] Li, Y.Y. (2014), Demand Driving and Ripple Effects of Housing Prices Rising: On Strategies to Deal with the Problems of Housing Price. China Economic Quarterly, (2): 443-463;

[7] Liang, Y.F., Xing, C.S. (2012), An Application Research on Dynamic Factor Model of Housing Prices Fluctuation: Based on 26 Cities' in China.

Mathematics in Practice and Theory, 42(6): 7-16;

[8] Luo, Z.Q., Liu, C., Picken, D. (2007), Housing Price Diffusion Pattern of Australia's State Capital Cities. Internationalof Strategic Property Management, 11(4): 227-242;

[9] Macdonald, R., Taylor, M. (1993), Regional House Prices in Britain: LongRun Relationships and Short-Run Dynamics. Scottish Journal of Political Economy, 40(1): 43-55;

[10] Meen, G. (1999), Regional House Prices and the Ripple Effect: A New Interpretation. Housing Studies, 14(6): 733-753;

[11] Meng, X.C., Zhang, Y.S., Li, T.Y. (2018), The Optimal Macro-prudential Policy for Effective Regulation of the Housing Market and "The Transfer of Capital from the Virtual to the Real". China Industrial Economics, (6): 81-97; [12] Milcheva, S., Zhu, B.(2015), Bank Integration and Co-movements across Housing Markets. Journal of Banking \& Finance, 72: 148-171;

[13] Pollakowski, H.O., Ray, T.S. (1997), Housing Price Diffusion Patterns at Different Aggregation levels:A Examination of Housing Market Efficiency. Journal of Housing Research, 8(1): 107-124;

[14] Tsai, I-Chun (2015), Spillover Effect between the Regional and the National Housing Markets in the UK. Regional Studies, 49(12): 1957-1976;

[15] Wang, S.T., Yang, Z., Liu, H.Y. (2008), An Empirical Study on the Interaction of Urban Housing Prices in China's Regional Market. Research on Financial and Economic Issues, (6): 122-129;

[16] Wang, X., Han, Y.H., Wang, C. (2018), Measurement of Connectedness and Spillove rs in China's Housing Market--Based on the DAG and Spillover Index Model. Journal of Applied Statistics and Management, 37(4): 713-727; [17] Wang, Y., Wang, D.L., Wang, S.J. (2013), Spatial Differentiation Patterns and Impact Factors of Housing Prices of China's Cities. Scientia Geographica Sinica, (10): 115 7-1165;

[18] Yu, H.Y. (2010), Are Economic Fundamentals or Real Estate Policies

Affecting China's Housing Prices? Finance \& Trade Economics, (3): 116-122. 